Superalloys 2012: $12^{\text {th }}$ International Symposium on Superalloys

\title{
POTENTIAL OF THE HALOGEN EFFECT FOR THE FORMATION OF A PROTECTIVE ALUMINA SCALE ON NI-BASE SUPERALLOYS
}

\author{
Hans-Eberhard Zschau, Michael Schütze \\ Dechema e. V., Karl-Winnacker-Institut, Theodor-Heuss-Allee 25, D-60486 Frankfurt am Main, Germany
}

Keywords: Ni-base alloys, oxidation protection, halogen effect, ion implantation, alumina scale

\begin{abstract}
The application of the halogen effect was extended to Ni-base superalloys with low aluminium content. A dense protective alumina scale can be formed by increasing the Al-activity through the halogen effect. Thermodynamic calculations predicted the existence of a region for the $\mathrm{F}$ - and Cl-effect for the alloys IN738 and IN939 at temperatures between $900^{\circ} \mathrm{C}$ and $1200^{\circ} \mathrm{C}$. The suitable F- and Cl-concentrations were found for IN738 by using ion implantation. The oxidation mechanism changed from an inward-growing discontinuous scale to a dense continuous protective alumina layer. The F-effect on IN738 improves the oxidation resistance during long term oxidation. By using the Feffect a pure alumina scale was also obtained for alloy CMSX-4.
\end{abstract}

\section{Introduction}

Poor oxidation resistance at temperatures above $1000^{\circ} \mathrm{C}$ is typical for technical Ni-base alloys with Al-contents of significantly less than $10 \mathrm{wt} \%$. These Al-concentrations are below the critical Alconcentration necessary for the formation of a dense protective alumina scale. A fast growing complex non-protective oxide scale covers the metal surface after short oxidation time. Below the oxide scale internal oxidation of aluminium takes place forming a discontinuous alumina scale which allows the diffusion of oxygen and nitrogen from the environmental atmosphere into the metal [1]. Al-rich coatings are commonly used to establish a protective alumina scale on the surface of components for high temperature technology [2-3]. According to Wagner`s theory of oxidation [4] a protective alumina scale can be formed if the Al-activity on the alloy surface is sufficiently high. The halogen effect [5] offers a new way to realize this condition. By using the halogen effect good results were obtained for TiAl-alloys [6-10]. First investigations applying the halogen effect to Ni-base alloys revealed the change of the oxidation mechanism from an internally growing discontinuous alumina scale to the formation of an externally growing dense protective alumina scale [11, 12]. In this work the halogen effect is applied to the alloys IN738, IN939 and CMSX-4. The predictions of the thermodynamical calculations to realize the halogen effect for $\mathrm{F}, \mathrm{Cl}$ and I are presented. The corresponding halogen concentrations were achieved by using ion implantation. The oxidation resistance during long term isothermal oxidation at $1050^{\circ} \mathrm{C}$ is investigated.

\section{Materials and Methods}

This work is focused on the Ni-base alloys IN738, IN939 and CMSX-4. Their elemental composition is summarized in table 1. After cutting into pieces of size $10 \times 10 \times 1 \mathrm{~mm}^{3}$ the specimens were polished down to 4000 grit $\mathrm{SiC}$. The fluorine ion implantation was performed at the ion implanter of the Institute of Nuclear Physics (IKF) of the Goethe-University in Frankfurt/Main. Prior to implantation the F- and Cl-implantation profiles were calculated by using the software package T-DYN [13] based on a Monte Carlo-model. The given implantation parameters (fluence, energy) have been varied for $\mathrm{F}$ between $1 \mathrm{x}$ $10^{16} \mathrm{~F} \mathrm{~cm}^{-2} / 38 \mathrm{keV}$ and $5 \times 10^{17} \mathrm{~F} \mathrm{~cm}^{-2} / 38 \mathrm{keV}$, whereas the Cl-fluences were chosen within $1 \times 10^{16} \mathrm{Cl} \mathrm{cm}^{-2} / 70 \mathrm{keV}$ and $4 \mathrm{x}$ $10^{17} \mathrm{Cl} \mathrm{cm}^{-2} / 70 \mathrm{keV}$. The ion energies correspond to a mean projected range of about $35 \mathrm{~nm}$ in the alloys for both $\mathrm{F}$ - and $\mathrm{Cl}$ ions as was obtained by using the energy-range calculation with TRIM 95 [14]. Only one side of the samples was implanted for the screening, and the untreated side served as a comparison. In case of the TGA-measurements both sides and all edges were implanted with fluorine. The PIGE (Proton Induced Gamma-ray Emission) technique [15] allowed the non-destructive measurement of the F-depth profiles. The resonant nuclear reaction ${ }^{19} \mathrm{~F}(\mathrm{p}, \alpha \gamma){ }^{16} \mathrm{O}$ at a proton energy of $484 \mathrm{keV}$ allowed the F-depth profiling up to a depth of $1 \mu \mathrm{m}$. By varying the incidence angle to 60 degrees a depth resolution of $10 \mathrm{~nm}$ near the surface could be obtained. The high-energetic $\gamma$-rays (5..7 MeV) were registered by using a NaI-detector. The implanted Cl-dose was determined by non-destructive RBS (Rutherford Backscattering Spectrometry) [15]. The backscattered He-ions were detected with a surface barrier detector. The PIGE and RBS-measurements were carried out at the 2.5 MV Van de Graaff - accelerator of the IKF. All oxidation tests were performed in a furnace under lab air at $1050^{\circ} \mathrm{C}$ up to 1000 hours. During the TGA-measurements a microbalance (Sartorius) recorded the mass gain simultaneously during isothermal oxidation in synthetic air. Metallographic crosssections were prepared to study the structure of the oxide scales by using light microscopy as well as SEM and EDX-spectrometry. For the thermodynamical calculations the software FactSage [16] was used. New databases for the Ni-base alloys and all halides (F, $\mathrm{Cl}, \mathrm{Br}$ and I) had been installed.

Table 1: Elemental composition of the Ni-base alloys investigated (in wt.\%).

\begin{tabular}{|l|c|c|c|}
\hline Element & IN738 & IN939 & CMSX-4 \\
\hline $\mathrm{Ni}$ & 61.13 & 48.35 & 61.7 \\
\hline $\mathrm{Co}$ & 9.0 & 20.0 & 10.0 \\
\hline $\mathrm{Cr}$ & 16.0 & 22.0 & 6.0 \\
\hline $\mathrm{Al}$ & 3.30 & 1.40 & 5.6 \\
\hline $\mathrm{W}$ & 1.70 & 2.0 & 6.0 \\
\hline $\mathrm{Mo}$ & 2.60 & - & 0.60 \\
\hline $\mathrm{C}$ & 0.17 & 0.15 & - \\
\hline $\mathrm{Ti}$ & 3.50 & 3.80 & 1.0 \\
\hline $\mathrm{Ta}$ & 1.70 & 1.30 & 6.0 \\
\hline Others & $0.90 \mathrm{Nb}$ & $1.0 \mathrm{Nb}$ & $3.0 \mathrm{Re} ; 0.1 \mathrm{Hf}$ \\
\hline
\end{tabular}

Principles Of The Halogen Effect For Ni-Base Alloys

The halogen effect can be described by the selective formation of gaseous Al-halides at high temperatures in pores and microcracks 
near the alloy surface. This model, originally developed for the case of TiAl-alloys [5] was applied to the Ni-base alloys. If the near-surface region of a Ni-base alloy is doped with a halide, e. g. fluorine, the formation of gaseous metal fluorides at high temperatures becomes possible. As a consequence mainly the Alfluorides migrate to the surface. The increasing oxygen partial pressure leads to the disintegration of the Al-fluorides and the formation of $\mathrm{Al}_{2} \mathrm{O}_{3}$. The free gaseous fluorine can partly return into the metal and reacts to form $\mathrm{Al}$-fluorides again. The continuation of this cycle process allows the formation of a dense protective alumina scale. The other alloying elements, mainly $\mathrm{Ni}$, remain in the metal because of the relatively low partial pressure of the corresponding metal fluorides. The most important reactions are summarized schematically in figure 1.

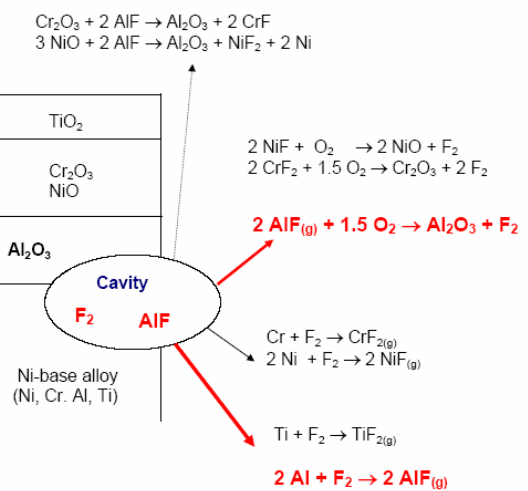

Figure 1: Possible reactions of fluorine within a cavity of a Nibase superalloy

\section{Thermodynamical Calculations for Halogens and Ni-Base Alloys}

\section{Results for Fluorine}

To identify a region of a selective formation of Al-fluorides, thermodynamic calculations were performed using the software FactSage for temperatures between $900^{\circ} \mathrm{C}$ and $1200^{\circ} \mathrm{C}$ on the alloys IN738 and IN939. The results obtained for $1100^{\circ} \mathrm{C}$ are illustrated in figure 2 . Beneath a critical pressure of $\mathrm{p}(\mathrm{AlF})_{\min }$,

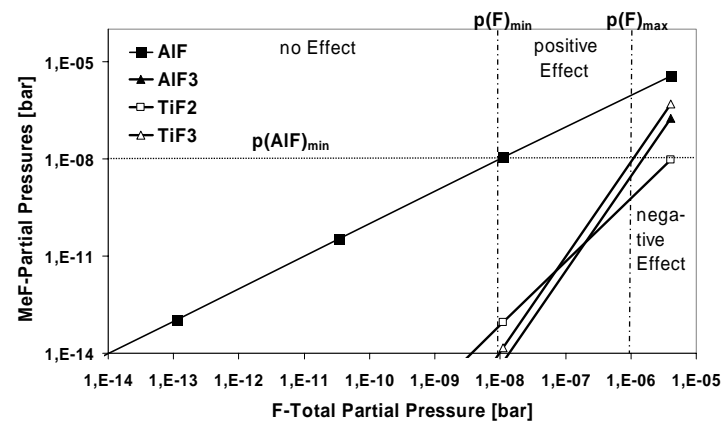

Figure 2: Window for a positive F-effect at $1100^{\circ} \mathrm{C}$ for the alloy IN738 [17]. The calculation was performed with FactSage. calculated by the growth kinetics of alumina [18], the amount of $\mathrm{Al}$ needed for further $\mathrm{Al}_{2} \mathrm{O}_{3}$ scale growth is too low. In this region no F-effect can occur. If the partial pressure of an $\mathrm{Al}-$ fluoride (here $\mathrm{AlF}$ ) meets the value of $\mathrm{p}(\mathrm{AlF})_{\min }$ at the point $\mathrm{p}(\mathrm{F})_{\min }$ the Al-transport becomes significant and the F-effect is open. The F-effect works until the partial pressure of the metal fluorides of other alloying elements $(\mathrm{Ni}, \mathrm{Co}, \mathrm{Cr}, \mathrm{Ti})$ reaches the critical pressure of $\mathrm{p}(\mathrm{AlF})_{\min }$ at $\mathrm{p}(\mathrm{F})_{\max }$ leading to the formation of a mixed oxide scale. As a consequence, a positive F-effect is possible only within the window $\left(\mathrm{p}(\mathrm{F})_{\max }-\mathrm{p}(\mathrm{F})_{\min }\right)$ of total fluorine partial pressures. The calculations for the temperatures between $900^{\circ} \mathrm{C}$ and $1200^{\circ} \mathrm{C}$ show the existence of a window defined by the limiting total $\mathrm{F}$-partial pressures $\mathrm{p}(\mathrm{F})_{\max }$ and $p(F)_{\min }$ for the alloy IN738. Figure 3 illustrates the corridor for the positive F-effect vs. temperature for the alloy IN738.

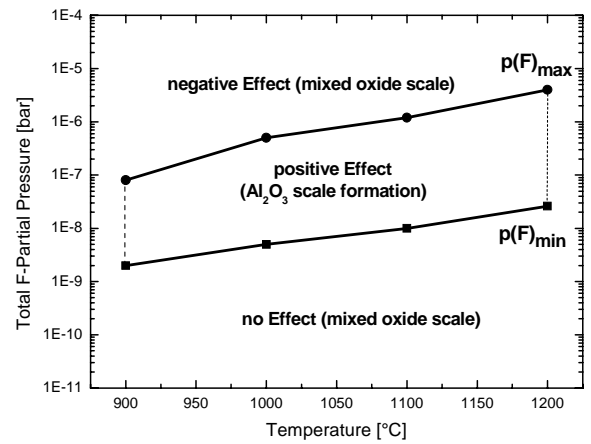

Figure 3: Corridor of a positive fluorine effect for the alloy IN738 between $900^{\circ} \mathrm{C}$ and $1200^{\circ} \mathrm{C}$.

The thermodynamical calculations for the alloy IN939 with a lower $\mathrm{Al}$-amount also predict the existence of a corridor for a positive $\mathrm{F}$ effect as depicted in figure 4.

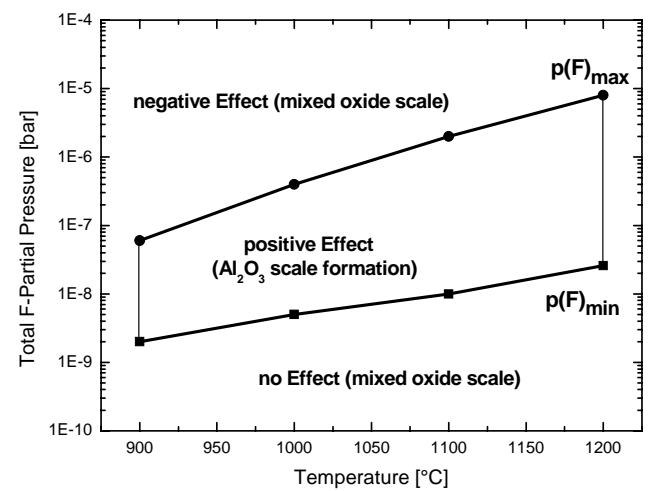

Figure 4: A positive F-effect is predicted for the alloy IN939 showing a corridor for temperatures between $900^{\circ} \mathrm{C}$ and $1200^{\circ} \mathrm{C}$. 
It is important to note that all calculations assume a thermodynamical equilibrium throughout. However the kinetic behaviour during instationary processes, e. g. the heating process, can not be explained by these calculations.

\section{Results for Chlorine}

If one modifies the reactions summarized in figure 1 by replacing $\mathrm{F}$ with $\mathrm{Cl}$ the mechanism of the Cl-effect is described. By applying these reactions for the thermodynamical calculations using FactSage similar results as in the fluorine case were obtained (Fig. 5). A critical pressure $\mathrm{p}(\mathrm{AlCl})_{\min }$ is required to ensure a significant transport of $\mathrm{Al}$ via the gaseous $\mathrm{Al}$-chlorides to

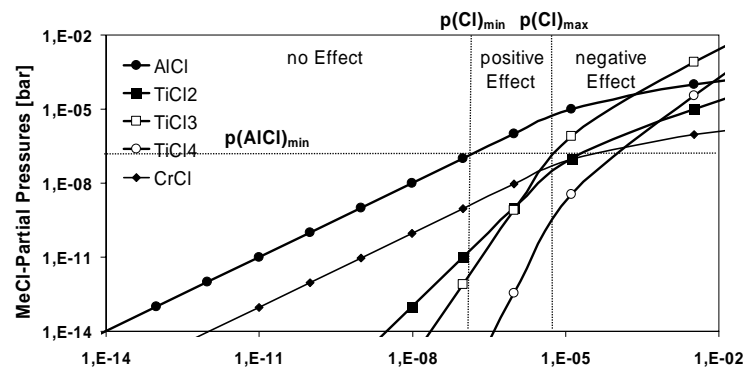

Figure 5: Window for a positive Cl-effect at $1100^{\circ} \mathrm{C}$ for the alloy IN738.

the surface. Below this critical pressure no Cl-effect will occur and a protective alumina scale will not be formed. By increasing the Cl-total partial pressure to $\mathrm{p}(\mathrm{Cl})_{\min }$ firstly the partial pressure of $\mathrm{AlCl}$ reaches this value which opens the Cl-effect. At a total Cl-partial pressure of $\mathrm{p}(\mathrm{Cl})_{\max }$ the gaseous $\mathrm{TiCl}_{3}$ meets this condition too.

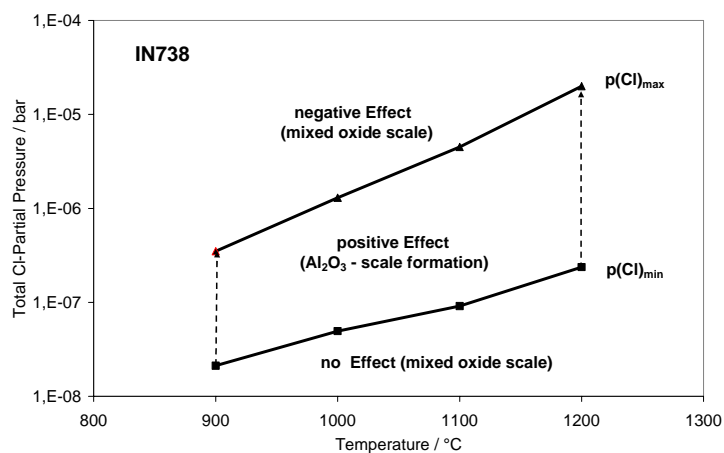

Figure 6: Corridor for the positive chlorine effect between $900^{\circ} \mathrm{C}$ and $1200^{\circ} \mathrm{C}$ for IN738.

From that point a simultaneous formation of gaseous $\mathrm{AlCl}$ and $\mathrm{TiCl}_{3}$ and their transport to the surface takes place leading to the growth of a non-protective mixed oxide scale. As a consequence the window for the Cl-effect is defined by the limiting partial pressures $\mathrm{p}(\mathrm{Cl})_{\min }$ and $\mathrm{p}(\mathrm{Cl})_{\max }$. If this condition is fulfilled the growth of a protective alumina scale is expected. The window for the Cl-effect was obtained for temperatures between $900^{\circ} \mathrm{C}$ and $1200^{\circ} \mathrm{C}$ revealing a corridor for the Cl-effect for the alloy IN738 as depicted in Fig. 6. The lower limit $\mathrm{p}(\mathrm{Cl})_{\min }$ is one order of magnitude higher than the lower limit $\mathrm{p}(\mathrm{F})_{\min }$ (see Fig. 3) indicating that the F-effect is more sensitive.

\section{$\underline{\text { Results for Iodine }}$}

The thermodynamic calculations with FactSage for iodine showed the absence of a window for the preferred formation of $\mathrm{Al}$ iodides. The gaseous species $\mathrm{CrI}$ and AlI meet the critical pressure $\mathrm{p}(\mathrm{AlI})_{\min }$ simultaneously. Hence no window for an iodine-effect can be defined. Similar results were obtained for bromine. Therefore the following investigations were focused on fluorine and chlorine.

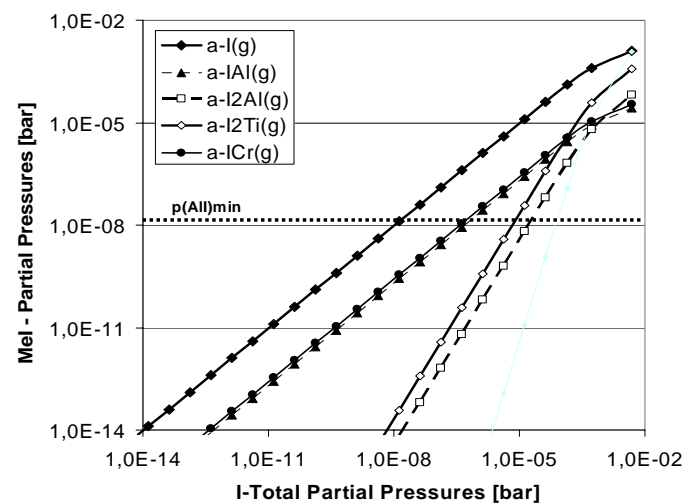

Figure 7: No window exists for a positive Iodine-effect at $1100^{\circ} \mathrm{C}$ and the alloy IN738.

\section{Fluorine-effect at Ni-Base alloys}

The limiting fluorine partial pressures $\left(\mathrm{p}(\mathrm{F})_{\min }, \mathrm{p}(\mathrm{F})_{\max }\right)$ obtained from thermodynamical considerations have to be transformed into a window of $\mathrm{F}$-concentrations $\left(\mathrm{c}(\mathrm{F})_{\min }, \mathrm{c}(\mathrm{F})_{\max }\right)$ useful for practical applications. Due to the absence of a direct equation between the fluorine partial pressures and the fluorine concentrations, they have to be determined by a screening. Because this screening is described in detail in $[12,19]$ only the main work packages are briefly described in this section. A welldefined F-doping of the alloy surface was achieved by using the ion implantation. Prior to implantation the F-implantation profiles have been calculated by using the software T-DYN based on a Monte Carlo model illustrated in Fig. 8. According to these results the implantations were performed by choosing fluences between $10^{16}$ and $4 \times 10^{17} \mathrm{~F} \mathrm{~cm}^{-2}$ corresponding to maximal Fconcentrations between 4 and 44 at.\%. The F-profiles could be verified by using the PIGE-technique. After oxidation between $24 \mathrm{~h}$ and $160 \mathrm{~h} / 1050^{\circ} \mathrm{C} /$ air cross-sections of the samples were prepared followed by SEM/EDX-studies of the oxide structure. A change of the oxidation mechanism was observed as depicted in Fig. 9 for a fluence of $4 \times 10^{17} \mathrm{~F} \mathrm{~cm}^{-2}$ after oxidation $\left(24 \mathrm{~h} / 1050^{\circ} \mathrm{C} / \mathrm{air}\right)$. Whereas the untreated alloy shows internal oxidation of $\mathrm{Al}$ beneath a $20 \mu \mathrm{m}$ thick chromia scale the implanted 
sample formed a 1-2 $\mu \mathrm{m}$ external growing protective alumina scale with a Ni-Al-spinel scale on top.

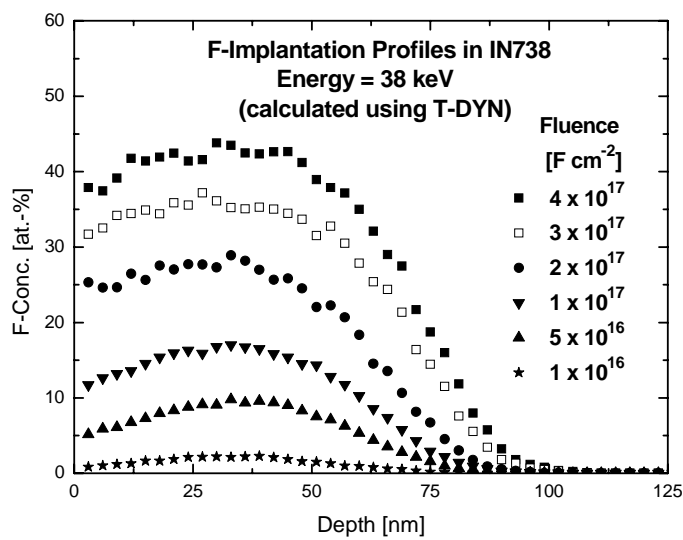

Figure 8: Calculated F-implantation profiles in the alloy IN738 by using the Monte Carlo software T-DYN [13].
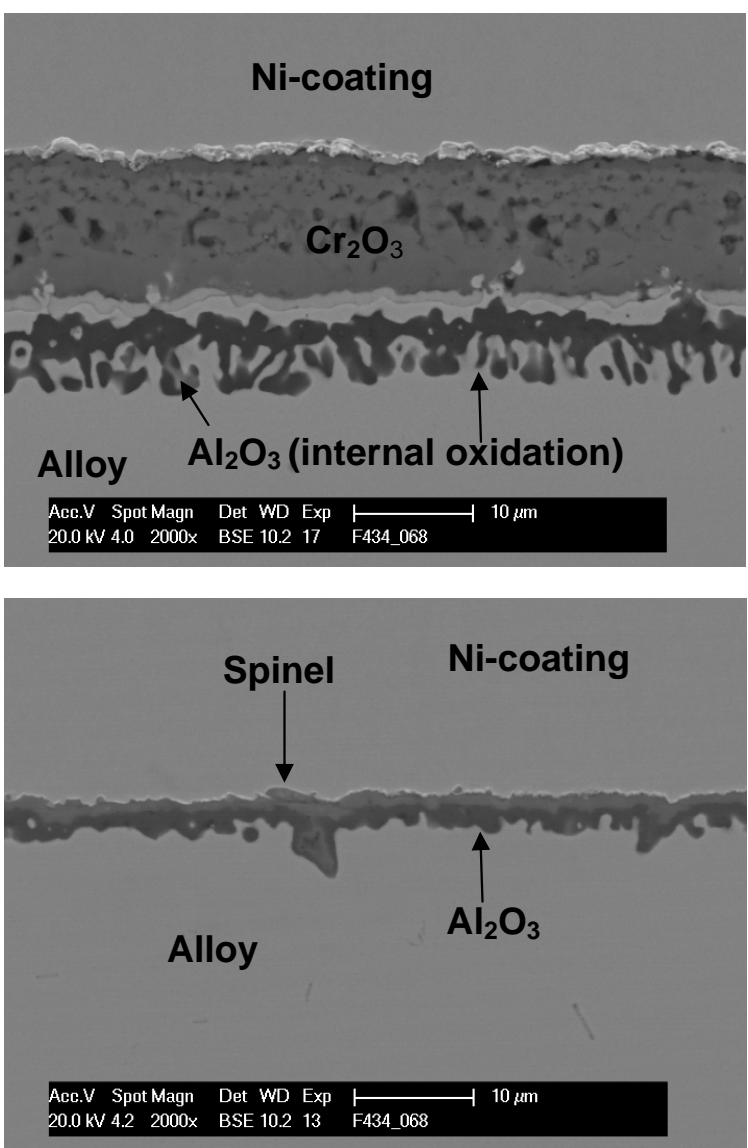

Figure 9: Oxide scale on the Ni-base alloy IN738. Top micrograph: Untreated sample after oxidation (24h/1050 $\left.{ }^{\circ} \mathrm{C} / \mathrm{air}\right)$. Bottom micrograph: Implanted sample (4 $\left.\mathrm{x} 10^{17} \mathrm{~F} \mathrm{~cm}^{-2} / 38 \mathrm{keV}\right)$ after oxidation $\left(24 \mathrm{~h} / 1050^{\circ} \mathrm{C} / \mathrm{air}\right)$.
For long term oxidation the best results were obtained with fluences between $5 \times 10^{16}$ and $10^{17} \mathrm{~F} \mathrm{~cm}^{-2}$ according to maximal

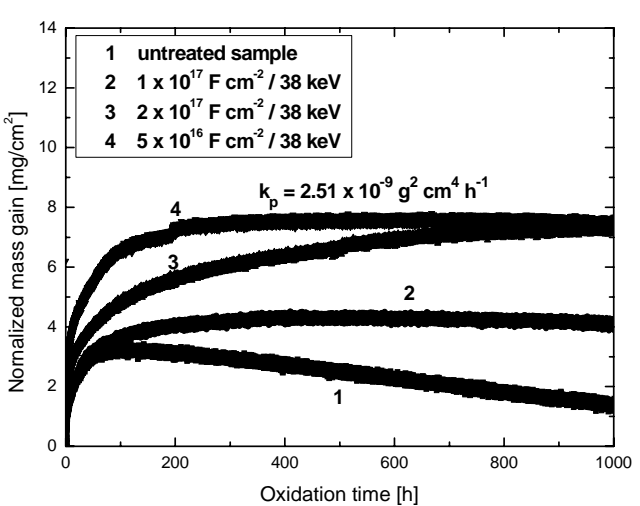

Figure 10: Mass gain during isothermal oxidation at $1050^{\circ} \mathrm{C} /$ air of F-implanted alloy IN738.
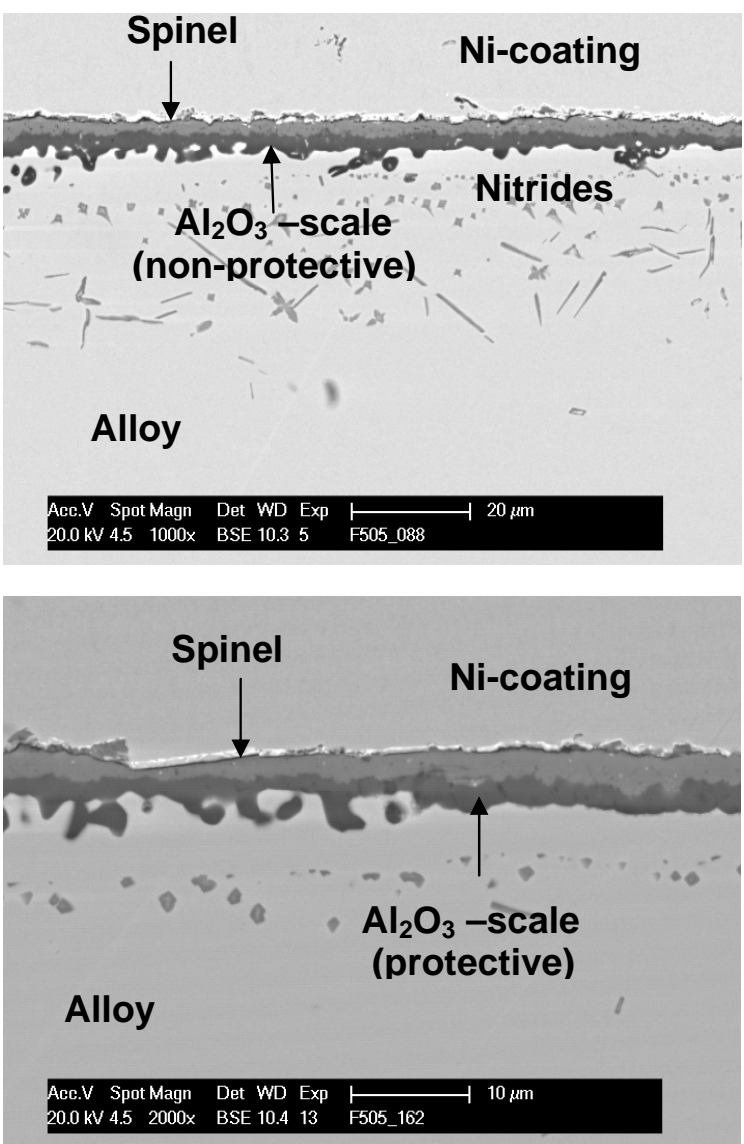

Figure 11: Oxide scale of an untreated (top micrograph) and an implanted (5 x $\left.10^{16} \mathrm{~F} \mathrm{~cm}^{-2} / 38 \mathrm{keV}\right)$ sample (bottom micrograph) of IN738 after isothermal oxidation (TGA $/ 1000 \mathrm{~h} / 1050^{\circ} \mathrm{C} / \mathrm{air}$ ). 
F-concentrations between $10-18$ at.\% as can be seen in Fig. 8 . The TGA-curves of IN738 implanted with fluences of $5 \times 10^{16}$, $10^{17}$ and $2 \times 10^{17} \mathrm{~F} \mathrm{~cm}^{-2}$ shown in Fig. 10 reveal a distinct mass gain within the first 100-200 hours. The high mass gain during the first 100-150h may be caused by the formation of metastable transient oxides. For the untreated sample a nearly linear mass loss during the following oxidation was observed. A fluence of 2 $x 10^{17} \mathrm{~F} \mathrm{~cm}^{-2}$ shows a parabolic behaviour but the kinetics is too fast. After implantation with $10^{17} \mathrm{~F} \mathrm{~cm}^{-2}$ the slow mass gain changes into a slow mass loss after 600 hours. In the case of $5 \mathrm{x}$ $10^{16} \mathrm{~F} \mathrm{~cm}^{-2}$ alumina kinetics are reached after $200 \mathrm{~h}$ characterized by a kinetic constant of $\mathrm{k}_{\mathrm{p}}=2.51 \times 10^{-9} \mathrm{~g}^{2} \mathrm{~cm}^{-4} \mathrm{~h}^{-1}$. At 900 hours a small mass loss is visible. To summarize, several processes can influence the TGA-curves: Formation of transient oxides during the first 100-150 $\mathrm{h}$ leading to a high mass gain, internal oxidation and nitridation, evaporation of gaseous species of the main alloy constituents (Cr, Ni, Ti) and scale spallation.
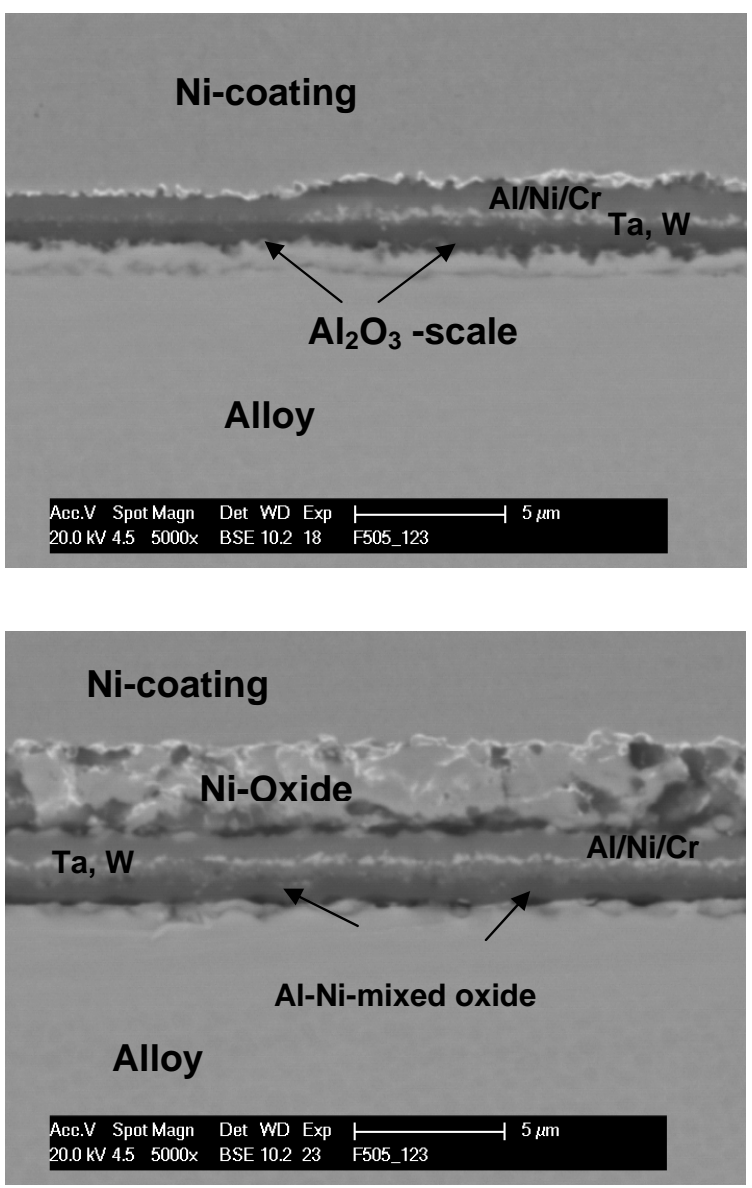

Figure 12: Top micrograph. The implanted alloy CMSX-4 $\left(10^{16} \mathrm{~F} \mathrm{~cm}^{-2}\right)$ forms a $0.5-1 \mu \mathrm{m}$ stoichiometric $\mathrm{Al}_{2} \mathrm{O}_{3}$.scale after oxidation $\left(60 \mathrm{~h} / 1050^{\circ} \mathrm{C} /\right.$ air $)$. Bottom micrograph: A complex oxide scale covers the surface of the untreated alloy.
The mass loss may be due to the evaporation processes and/or the spallation of outer scales like chromia or spinel. However the SEM-study of the metallographic cross-sections reveals the protective scale structure as shown in Fig. 11. The untreated sample (Fig. 11, top micrograph) is covered with a 2-3 $\mu \mathrm{m}$ thick alumina scale showing internal oxidation and a top scale of spinel. The outer chromia scale had spalled. Additionally nitrides are formed beneath the alumina scale up to a depth of 30-40 $\mu \mathrm{m}$. In contrast to this a $1-2 \mu \mathrm{m}$ thick protective alumina scale was established on the sample implanted with $5 \times 10^{16} \mathrm{~F} \mathrm{~cm}^{-2} / 38 \mathrm{keV}$ after oxidation $\left(1000 \mathrm{~h} / 1050^{\circ} \mathrm{C} / \mathrm{air}\right)$ as illustrated in Fig. 11, bottom micrograph. The alumina scale is covered with $\mathrm{Ni}-\mathrm{Al}-$ spinel. Only a few nitrides are visible.

Although the F-effect for the alloy IN939 was predicted by thermodynamical considerations (Fig. 4) no effect was found after ion implantation and subsequent oxidation at $1050^{\circ} \mathrm{C}$. This may be due to the low Al-content which hinders the formation of a suffucient amount of Al-fluorides.

The F-effect was observed for the alloy CMSX-4 and implantation parameters of $10^{16} \mathrm{~F} \mathrm{~cm}^{-2} / 38 \mathrm{keV}$ (Fig. 12). After oxidation $\left(60 \mathrm{~h} / 1050^{\circ} \mathrm{C} /\right.$ air) a $0.5-1 \mu \mathrm{m}$ thick stoichiometric $\mathrm{Al}_{2} \mathrm{O}_{3}$ - scale was found at the metal/oxide - interface (Fig. 12, top micrograph). Above this scale a $0.5 \mu \mathrm{m} \mathrm{Al-Ni-mixed} \mathrm{oxide}$ scale with inclusions of Ta and W was formed. The outer scale of $1 \mu \mathrm{m}$ thickness consists of Al-Ni-Cr-mixed oxide. The untreated alloy shows an Al-Ni-mixed oxide scale at the metal/oxideinterface, covered with a layer rich in Ta and $\mathrm{W}$ and a $\mathrm{Al}-\mathrm{Ni}-\mathrm{Cr}$ mixed oxide scale. The outer scale of $3 \mu \mathrm{m}$ thickness consists of Ni-oxide (Fig. 12, bottom micrograph).

\section{Chlorine-Effect for Ni-Base Alloys}

The Cl-effect predicted by thermodynamical calculations was detected for the first time at a Ni-base alloy. Based on the T-DYN calculations for the Cl-implantation into IN738 a screening was

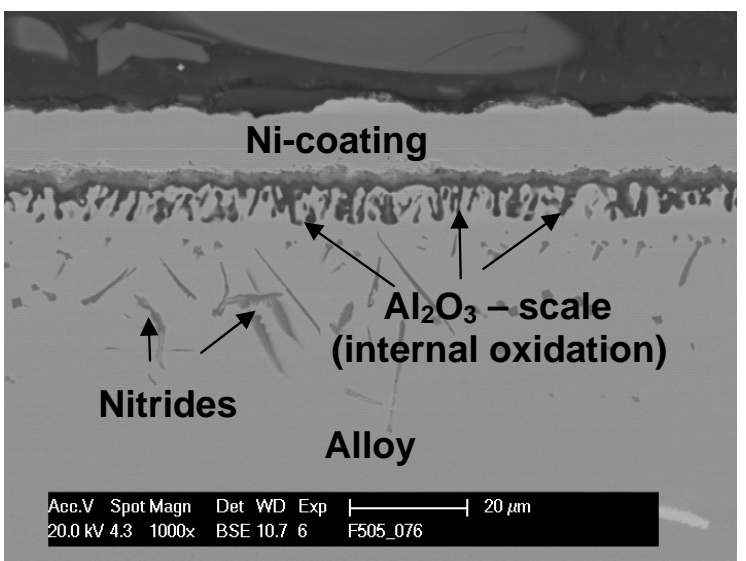

Figure 13: The oxide scale of untreated IN738 after isothermal oxidation $\left(60 \mathrm{~h} / 1050^{\circ} \mathrm{C} /\right.$ air $)$ shows distinct internal oxidation of aluminium. Additionally nitrides were formed within the subsurface zone of the alloy. 


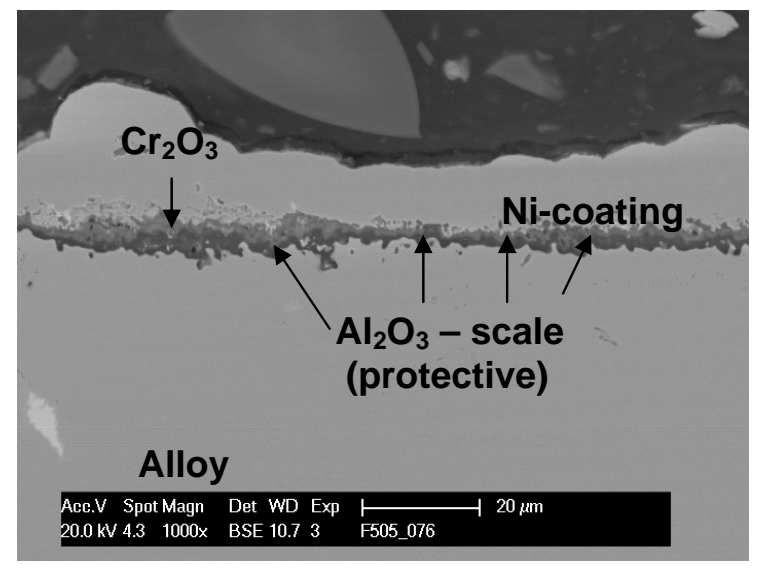

Figure 14: Detection of the Cl-Effect on Ni-base alloys: A protective alumina scale was formed on Cl-implanted IN738 $\left(2 \times 10^{17} \mathrm{Cl} \mathrm{cm}^{-2} / 70 \mathrm{keV}\right)$ after isothermal oxidation $\left(60 \mathrm{~h} / 1050^{\circ} \mathrm{C} / \mathrm{air}\right)$.

done with fluences between $10^{16}$ and $4 \times 10^{17} \mathrm{Cl} \mathrm{cm}^{-2}$. The ion energy of $70 \mathrm{keV}$ corresponds to a mean projected Cl-ion range of $35 \mathrm{~nm}$ in the alloy. Whereas the unprotected alloy is shown in Fig. 13, the Fig. 14 illustrates the Cl-effect at implanted IN738 (2 x $\left.10^{17} \mathrm{Cl} \mathrm{cm}^{-2}\right)$ after oxidation $\left(60 \mathrm{~h} / 1050^{\circ} \mathrm{C} /\right.$ air $)$.

Below a 2-5 $\mu \mathrm{m}$ thick partly spalled $\mathrm{Cr}_{2} \mathrm{O}_{3}$ - top scale a pronounced internal oxidation of $\mathrm{Al}$ was found (Fig. 13). The nonprotective alumina scale can not inhibit the inward diffusion of nitrogen leading to the formation of needle-like Ti-nitrides within the subsurface zone up to a depth of about $30 \mu \mathrm{m}$. However the implanted sample is covered with a $1 \mu \mathrm{m}$ thin protective alumina scale with a partly spalled chromia scale on top. No nitrides are visible at the metal/oxide interface indicating the protective nature of the alumina scale (Fig. 14).

\section{Conclusions}

A new method was presented for Ni-base alloys with 3-5 wt.\% Al-content to establish a protective alumina scale instead of the discontinuous non-protective inward growing alumina scale. The halogen effect was proposed to increase the Al-activity. Based on thermodynamical calculations with fluorine and chlorine the existence of a window for the halogen effect was shown for the Ni-base alloys IN738 and IN939 at temperatures between 900 and $1200^{\circ} \mathrm{C}$. Each window is defined by a minimum and a maximum partial pressure of the halogen. In the case of bromine and iodine no halogen effect was predicted. A screening by using ion implantation was performed for the alloys IN738 and IN939 to transform the window for the partial pressures into a window in terms of halogen concentrations. In the case of IN738 windows for the F-effect and the Cl-effect were found and the corresponding fluences and concentrations were determined. The optimal implantation parameters for $\mathrm{F}$ are between $5 \times 10^{16}$ and $10^{17} \mathrm{~F} \mathrm{~cm}^{-2} / 38 \mathrm{keV}$, whereas for $\mathrm{Cl}$ it is $2 \times 10^{17} \mathrm{Cl} \mathrm{cm}^{-2} / 70 \mathrm{keV}$, resp. The formation of a dense protective alumina scale was achieved for oxidation at $1050^{\circ} \mathrm{C}$. The long term isothermal oxidation behaviour up to $1000 \mathrm{~h} / 1050^{\circ} \mathrm{C}$ investigated by TGA reveals significant decrease of the oxidation rate. Due to their low Al-content the alloy IN939 is unable to establish a protective alumina scale. After implantation with $10^{16} \mathrm{~F} \mathrm{~cm}^{-2} / 38 \mathrm{keV}$ the formation of a pure alumina scale was also observed for the alloy CMSX-4.

\section{Acknowledgment}

The work was supported to a large extent by the Deutsche Forschungsgemeinschaft (DFG) under contracts SCHU 729/18-1 and SCH 729/18-2 which is gratefully acknowledged.

\section{References}

1. Litz., A. Rahmel, M. Schorr and J. Weiss, "Scale Formation on the Ni-Base Superalloys IN 939 and IN 738 LC," Oxidation of Metals, 32 (1989), 167- 184.

2. C. Leyens, U. Schulz and K. Fritscher, "Oxidation and lifetime of PYSZ and CeSZ coated Ni-base substrates with MCrAIY bond layers, "Microscopy of Oxidation," 1 (2004), 229-234.

3. W.J. Quadakkers, V. Shemet, D. Sebold, R. Anton, E. Wessel and L. Singheiser, "Oxidation Characteristics of a Platinized MCrAlY Bond Coat for TBC Systems during Cyclic Oxidation at $1000^{\circ} \mathrm{C}$," Surface \& Coatings Technology, 1 (2005), 77-82.

4. Per Kofstad, High Temperature Oxidation of Metals, (New York, N. Y., Elsevier Publishing Company, 1988).

5. A. Donchev, B. Gleeson and M. Schütze, "Thermodynamic Considerations of the Beneficial Effect of Halogens on the Oxidation Resistance of TiAl-Based Alloys,” Intermetallics, 11 (2003), 387-398.

6. H.-E. Zschau, V. Gauthier, G. Schumacher, F. Dettenwanger, M. Schütze, H. Baumann, K. Bethge and M. Graham, "Investigation of the Fluorine Microalloying Effect in the Oxidation of TiAl at $900^{\circ} \mathrm{C}$ in Air," Oxidation of Metals, 59 (2003), 183-200.

7. H.-E. Zschau, M. Schütze, H. Baumann and K. Bethge, "The Quantitative Role of Surface Doped Fluorine for the Improvement of Oxidation Resistance of TiAl in Air," Materials Science Forum, 505 (2004), 461- 464.

8. H.-E. Zschau, M. Schütze, H. Baumann and K Bethge, "Application of ion beam analysis for the control of the improvement of the oxidation resistance of $\mathrm{TiAl}$ at $900{ }^{\circ} \mathrm{C}$ in air by fluorine ion implantation and HF-treatment," Nuclear Instruments and Methods in Physics Research B, 240 (2005), 137-141.

9. H.-E. Zschau, M. Schütze, H. Baumann and K. Bethge, “The time behaviour of surface applied fluorine inducing the formation of an alumina scale on gamma-TiAl during oxidation at $900^{\circ} \mathrm{C}$ in air,” Intermetallics, 14 (2006), 1136-1142.

10. A. Donchev, E. Richter, M. Schütze and R. Yankov, "Improvement of the Oxidation Behaviour of TiAl-alloys by Treatment with Halogens,” Intermetallics, 14 (2006), 1168-1174. 
11. H.-E. Zschau, D. Renusch, P. Masset and M. Schütze, “A new concept of oxidation protection of Ni-base alloys by using the halogen effect, "Materials at High Temperatures, 26 (2009), 8589.

12. H.-E. Zschau, D. Renusch, P. Masset and M. Schütze, "The halogen effect for Ni-base alloys - a new method for increasing the oxidation protection at high temperatures," Nuclear Instruments and Methods in Physics Research B, 267 (2009), 1662-1665.

13. J. Biersack, "TRIM-DYNAMIC applied to marker broadening and SIMS depth profiling”, Nuclear Instruments and Methods in Physics Research B, 153 (1999), 398-409.

14. J. Ziegler, J. Biersack and U. Littmark, The stopping and range of ions in solids, (New York, Pergamon Press, 1995).

15. J. R. Tesmer and M. Nastasi (Eds.), Handbook of Modern Ion Beam Materials Analysis, (Pittsburgh, P.A., Materials Research Society, 1995).

16. Program System FactSage Version 4.5.1 Fa. GTT, Herzogenrath

17. H.-E. Zschau, P. J. Masset and M. Schütze, The Halogen Effect for Ni-Base Superalloys - a Thermodynamic Study. Materials Science Forum, Vols. 638-642 (2010), 2375-2380.

18. J. W. Fergus, "Review of the effect of alloy composition on the growth rates of scales formed during oxidation of gamma titanium aluminide alloys," Materials Science and Engineering, A338 (2002) 108-125.

19. H.-E. Zschau, P. J. Masset and M. Schütze, "Screening of the Fluorination Parameters to Improve the Oxidation Resistance of Ni-Base Superalloys at Elevated Temperatures," ECS Transactions, 25 (25) (2010), 21-30. 